\title{
What is the Functional / Organic Distinction Actually Doing in Psychiatry and Neurology?
}

\author{
Authors: \\ Vaughan Bell ${ }^{1,2}$, Sam Wilkinson ${ }^{3}$, Monica Greco ${ }^{4}$, \\ Callum Hendrie ${ }^{5}$, Ben Mills ${ }^{5}$, Quinton Deeley ${ }^{2,6}$
}

1. Research Department of Clinical, Educational and Health Psychology, University College London

2. South London and Maudsley NHS Foundation Trust

3. Department of Sociology, Philosophy and Anthropology, Exeter University

4. Department of Sociology, Goldsmiths, University of London

5. Headway East London

6. Institute of Psychiatry, Psychology \& Neuroscience, King's College London

Corresponding author:

Dr Vaughan Bell

Vaughan.Bell@ucl.ac.uk 


\begin{abstract}
The functional-organic distinction aims to distinguish symptoms, signs, and syndromes that can be explained by diagnosable biological changes, from those that cannot. The distinction is central to clinical practice and is a key organising principle in diagnostic systems.

Following a pragmatist approach that examines meaning through use, we examine how the functional-organic distinction is deployed and conceptualised in psychiatry and neurology. We note that the conceptual scope of the terms 'functional' and 'organic' varies considerably by context. Techniques for differentially diagnosing 'functional' and 'organic' diverge in the strength of evidence they produce as a necessary function of the syndrome in question.

Clinicians do not agree on the meaning of the terms and report using them strategically. The distinction often relies on an implied model of 'zero sum' causality and encourages classification of syndromes into discrete 'functional' and 'organic' versions. Although this clearly applies in some instances, this is often in contrast to our best scientific understanding of neuropsychiatric disorders as arising from a dynamic interaction between personal, social and neuropathological factors. We also note 'functional' and 'organic' have loaded social meanings, creating the potential for social disempowerment and epistemic injustice. Given this, we argue for a better understanding of how strategic simplification and complex scientific reality limit each other. We also note that the contribution of people who experience the interaction between 'functional' and 'organic' factors has rarely informed the validity of this distinction and the dilemmas arising from it, and we highlight this as a research priority.
\end{abstract}




\section{Introduction}

The functional-organic distinction attempts to differentiate symptoms, signs and syndromes that can be explained by diagnosable biological changes from those that cannot (Kendler, 2012). It has been a central conceptual tool used to categorise cause and organise diagnosis in neuroscientific medicine (Beer, 1996a; Reynolds, 1990). It is cited as one of the main distinguishing characteristics of patients seen by, and referred to, psychiatrists and neurologists (Martin, 2002). It remains one of the central organising principles in current diagnostic systems, despite efforts to deemphasise the distinction in recent years (Tyrer, 2014).

The distinction has long been derided. In his landmark textbook of neurology, Wilson (1940) wrote that the functional-organic distinction "lingers at the bedside and in medical literature, though it is transparently false and has been abandoned long since by all contemplative minds". More recently it has been criticised for maintaining an artificial distinction between psychiatry and neurology (Zeman, 2014), promoting naïve dualism in neuroscientific medicine (Kendler, 2012), promoting diagnostic incoherence (Sachdev, 1996), and encouraging the continued stigmatisation of mental health problems (Ungar and Knaak, 2013).

Although there has been much discussion of the required conceptual basis of the functionalorganic distinction, much less has been written on how it is actually used in practice.

Following a pragmatist approach to conceptual analysis in psychology and medicine (Cornish and Gillespie, 2009; Lewis, 2007), we examine how the functional-organic distinction has been, and is, used in medical classification, by clinicians, and in research. We use this analysis to highlight inconsistencies and contradiction. We go on to illustrate the many roles the functional-organic distinction attempts to fulfil, and then suggest how future research programmes could address some of the practical and conceptual shortcomings we identify.

\section{Historical shifts in the meaning of 'functional' and 'organic'}

Although the history of the functional-organic distinction has been discussed in more detail elsewhere (Beer, 1996a; Berrios et al., 2003; Reynolds, 1990), a brief historical account is useful to understand how the terms have changed in meaning and scope over the course of their use.

Physician Thomas Willis (1621-1675) first used the term 'neurology' when connecting the signs and symptoms of patients to alterations in the structure of the nervous system, usually identified in post-mortem dissection (Arráez-Aybar et al., 2015; Molnár, 2004). This method was later developed and cited a visible structural lesion as one of the most important elements in the conceptualisation of an organic disorder (Goetz, 2009), something that remains influential to this day. For early neurologists following Willis, the term "functional" had two potential meanings (Trimble, 1982) - referring to diseases where aetiology could be explained by neurophysiological changes despite no evidence of a structural lesion (e.g. via seizures or metabolic disturbance), and alternatively, to problems with intellectual and emotional functioning with no attempt to link these difficulties to specific neurophysiological 
mechanisms. Later, William Cullen (1710-1790) published an influential classification that cited all 'neuroses' - a category of all 'nervous diseases' including all forms of madness - as 'organic' states (Berrios et al., 2003; Cullen, 1780). However, subsequent $19^{\text {th }}$ Century debates about the nature of insanity frequently proposed conflicting views about the necessity of structural lesions, physiological disturbances, or psychological changes for causation of what we would now call psychiatric or neurological disorders (Beer, 1996b; Berrios and Beer, 1994).

William Gowers (1845-1915) first introduced the functional-organic distinction as an explicit explanatory contrast in neurology. He cited visible structural lesions as the basis of 'organic' disorders and alterations to physiology as the basis of 'functional' disorders (Gowers, 1898). In these debates, the term 'functional' rarely meant 'non-organic' but typically referred to physiological disturbance which could not be adequately established by existing diagnostic methods (Beer, 1996a). Later, dynamic psychiatrists, "took over" (Reynolds, 1990) the term 'functional' to mean 'explained by the principles of psychoanalysis' and so applied to both psychosis and neurosis. Although this use implied a disturbance of the nervous system in a broad sense, the assumption that such difficulties would eventually be explained by, or reduced to, specific instances of altered neurophysiology was rejected.

More recently, the mid- $20^{\text {th }}$ Century birth of cognitive psychology and computational approaches to the mind saw a conceptual shift. 'Functional' was associated with software and the mind, and 'organic' with hardware and the brain. Neuropsychiatric disorders were therefore interpreted in this light, suggesting that syndromes could be explained by impairment to distinct levels of function - either information processing (functional) or implementation (organic) (Kahn and Arbib, 1973; Kendler, 2012; Pylyshyn, 1978).

Diagnostically, the functional-organic distinction was present in the first edition of the Diagnostic and Statistical Manual of Mental Disorders (DSM-I), with substantial concordance between the largely unchanged definition in DSM-II and the eighth edition of the International Classification of Diseases (ICD-8) (Sanders, 2011). This took the form of the "organic brain syndrome" diagnosis that described a syndrome of impairments to orientation, memory, intellectual functions, judgment, lability, and shallowness of affect. It explicitly excluded disorders that present predominantly with changes to personality or affect - or where thought disorder or isolated perceptual alterations were present. The diagnostic criteria additionally described the syndrome as presenting as "mild, moderate, or severe, but most of the basic symptoms of the syndrome are generally present to a similar degree in any one patient at any one time" (Fauman, 1977). Here, "organic brain syndrome" was a narrow diagnosis that excluded many problems that would be considered typically 'organic' in modern clinical practice. This was revised in the DSM-III to require additional evidence of neurological damage and to allow a wider range of phenomena to be considered 'organic', including the option to classify some close equivalents of 'functional' diagnoses (disorders of mood, personality, psychosis etc) as 'organic' (Lipowski, 1985) making an explicit divide between similar syndromes with distinct aetiologies. 
More recently, diagnostic manuals have attempted to de-emphasise the functional-organic distinction although the changes are mostly cosmetic - by altering the terminology used to refer to 'organic' and changing how diagnoses are grouped. Psychiatric syndromes are now more commonly labelled as "secondary" to "disorders or diseases classified elsewhere" or "due to another medical condition" rather than 'organic' in both the DSM-5 and ICD although the implications are virtually identical. Similarly, there has been an attempt to increasingly group diagnoses by domain. The DSM no longer has a separate section for 'organic' disorders but has included all such disorders under general syndrome categories in the DSM-5. For example, the DSM-5 diagnosis "Depressive Disorder Due to Another Medical Condition" is now listed in the "Depressive Disorders" chapter rather than in a separate chapter for 'organic' disorders, as occurred with earlier DSM editions (e.g. in the DSM-IV it appears in "Mental Disorders Due to Another Medical Condition"). To a lesser extent this approach has been applied to the ICD-11. For example, all sleep problems, previously split between sections for functional and organic disorders are now all grouped under the "Sleep-wake disorders" category. 'Organic' disorders also maintain their own distinct category in the ICD-11 (6E6 "Secondary mental or behavioural syndromes associated with disorders or diseases classified elsewhere"). Nevertheless, the pattern of having both 'functional' and 'organic' versions of major psychiatric syndromes remains largely unchanged.

Although not a complete historical account, we present these examples to illustrate how the categories 'functional' and 'organic' have not retained a consistent meaning, scope, or relationship to diagnostic categorisation during the history of their use. Historically, 'madness' has been considered as primarily 'organic' or primarily 'functional' at different times or by different classification schemes, regardless of neurological findings. Brain pathologies without structural lesions (such as seizures) have been included in both 'functional' and 'organic' categories at different times. Diagnostically, 'organic' has been used to label a specific syndrome of cognitive disturbance that explicitly excludes certain neurological disorders (as in the DSM-II diagnosis of "organic brain syndrome") or categories of psychiatric syndromes akin to 'functional' diagnoses but accompanied by diagnosable neuropathology (e.g. "organic psychosis"). However, regardless of the specific changes, one consistent characteristic has been the importance of the functional-organic distinction as a major factor in how diagnostic categories have been organised.

\section{Inconsistencies in the contemporary use of the functional-organic distinction}

The inconsistent meaning of 'functional' and 'organic' is not solely a historical issue. In this section, we highlight contemporary problems and inconsistencies apparent in the scope, diagnosis, understanding and political use of the functional-organic distinction.

\section{Inconsistencies in the conceptual scope of the functional-organic distinction}

Although the functional-organic distinction is often cited as a tool used to differentially diagnose 'organic' from 'non-organic' disorders (David, 2009), the terms 'functional' and 'organic' are clearly deployed in ways that indicate more complex scope when used in practice. 
'Functional' is often used to indicate that there is no diagnosable pathophysiology sufficient to account for the aetiology of the symptoms - as implied by the use of the term 'functional psychiatric disorder'. However, this applies to some diagnoses and not others, despite them being identical in this regard. For example, discussion of 'functional psychosis' (FryarWilliams and Strobel, 2016) and 'functional depression' (Starkstein et al., 1989) but not 'functional autism' or 'functional Tourette syndrome'.

Indeed, tic disorders are diagnosed solely on behavioural characteristics, and, in fact, specifically require the exclusion of "underlying neurological disorder" (e.g. F95 Tic disorders, ICD-10) and so might be considered 'functional'. However, 'functional' or 'psychogenic' tics are considered to be a distinct category from tics diagnosed using tic disorder criteria which are considered 'organic' (Baizabal-Carvallo and Fekete, 2015; Demartini et al., 2015). This is also despite the existence of tic disorders that are attributed to the direct effects of neurological disorders such as traumatic brain injury (Krauss and Jankovic, 1997; Ranjan et al., 2011) and stroke (Gomis et al., 2008; Kwak and Jankovic, 2002). As currently used, 'organic' tic disorder refers to the diagnosis established through the orthodox diagnostic criteria that excludes neurological damage, but also refers to tic disorder after acquired brain injury, while 'functional' refers to tic disorder without neurological damage but with atypical presentation and 'psychological' causation. Here, the conceptualisation of 'organic' in tic disorders covers what would otherwise be considered 'functional' in other disorders.

One important use of 'functional' is to categorise disorders that appear 'organic' but aren't (Kanaan et al., 2012). For example, 'functional neurological disorders' are disorders that present similarly to neurological disorders but without evidence for impaired neurophysiology in the individual patient that would explain the disability, indicating their aetiology is 'not organic' (Espay et al., 2018). However, the use of 'functional' more broadly to signal 'not organic' may solely refer to diagnosable damage to the nervous system, or may also include disorders that include damage to other bodily systems. For example, the 'functional erectile dysfunction' indicates an erectile problem in the absence of neurological or vascular impairment (Farre et al., 2004). Here, both uses of 'functional' imply 'not organic' but the scope to which 'organic' refers, differs.

With the rise of 'functional neurological disorder' as the preferred terminology for conditions previously labelled 'hysteria' or 'psychogenic' (Edwards et al., 2014), authors have been increasingly careful to distinguish between functional disorders, malingering and other forms of illness deception (Stone et al., 2002). Nevertheless, disability that presents like neurological disorder but arises without diagnosable damage to the nervous system and is not under voluntary control ('functional neurological disorder'), is still often grouped together with the faking of symptoms under the banner of 'functional' syndrome or disorder (Berry, 2000; Enzenauer et al., 2014; Silber, 1985). Here, problems of markedly different causation, and indeed, a markedly different nature, are equally referred to as 'functional'. 
These cases illustrate that 'functional' and 'organic' are often used to indicate 'not the other', although the scope of the 'other' varies greatly depending on the context of use.

\section{Reliance on different diagnostic approaches that produce varying degrees of certainty}

The distinction between 'functional' and 'organic' is often treated as if the distinction is selfevident within diagnostic systems and is used as an unambiguous exclusion criteria in research ("Patients were excluded if they had an organic disorder") and a maxim in clinical practice ("Always exclude organic causes of psychiatric symptoms") (Amad et al., 2015). In practice, however, this process can be far more complex, and far more uncertain, than such statements would suggest.

David (2009) has noted that "it is clear that the line of demarcation between organic and nonorganic psychiatric disorders is not hard and fast, and in a substantial number of cases there can be continuing uncertainty" although stresses that this is not an excuse to abandon "very real distinctions between classes of disorder". Importantly, we are not arguing here for abandoning the functional-organic distinction as entirely incoherent or futile. Indeed, there are clearly problems that unambiguously arise as a result of diagnosable biological changes, and clearly those that arise without. Nevertheless, ambiguity is probably the rule rather than exception in many practical instances of differential diagnosis.

One of the central tasks in making this distinction is attributing causality. Even when disturbed physiology is identified, clinicians then need to confidently identify it as the cause of the relevant signs or symptoms. Lishman's criteria (cited in David, 2009) suggests that organic disorders are diagnosed on the basis of "a high probability that appropriate examination and investigation will uncover some cerebral or systemic pathology responsible for, or contributing to, the mental condition". What counts as "high probability" here remains undefined and, often, largely unexamined. In fact, the extent to which diagnosable biological changes need to be established, or causality can be confidently attributed, varies significantly between disorders as an inherent consequence of their diagnostic criteria and the investigative methods that become relevant because of them.

Delirium, a confusional state involving disturbances to cognition, behaviour and emotion, has a varying relationship to diagnosed physiological change in diagnostic manuals. In the ICD10, "F05 Delirium, not induced by alcohol and other psychoactive substances" is an organic disorder but requires no physiological findings for confirmation. If someone fulfils the criteria for delirium ("disturbances of consciousness and attention, perception, thinking, memory, psychomotor behaviour, emotion, and the sleep-wake schedule") they have an organic disorder by definition. The DSM-5 definition of delirium lists similar symptoms but includes the specifier that "There is evidence from the history, physical examination, or laboratory findings that the disturbance is a direct physiological consequence of another medical condition" although does not state how to establish what counts as a "direct physiological consequence". Diagnostically, delirium is defined in a way that implies its organic nature from its presentation to the point where, in one definition, no further investigation is necessary and in another, simply stating it should be a 'physiological 
consequence' is sufficient, despite the fact that the causes of delirium are typically nonspecific and multifactorial (Lee et al., 2019).

In some cases, an organic basis for a disorder can be established through a hypotheticodeductive approach. For example, a patient presenting with symptoms fulfilling a DSM-5 diagnosis of panic disorder and hypercalcemia may suggest the hypothesis that the anxiety symptoms are primarily caused by hyperparathyroidism, which can cause a disturbance in blood calcium levels and increase anxiety. If the anxiety symptoms resolve or reduce after high calcium levels are treated, a diagnosis of an organic anxiety syndrome is recommended (Geffken et al., 1998). Here a diagnosis is based on a mechanistic understanding of the pathophysiology, and an interventionist approach to hypothesis testing.

Other forms of 'organic' aetiology are established through apparent temporal relationship between the incident disturbance of the nervous system and the onset of psychiatric symptoms. Indeed, the psychoses of epilepsy are primarily diagnosed based on their temporal relationship to seizure events (Maguire et al., 2018) and substance-induced psychosis is primarily diagnosed based on its temporal relationship to drug use (Wilson et al., 2018). However, the extent to which the timing of these events can be confidently established is likely to vary due to the reliability of the informants, and the difficulty with judging the onset of psychosis itself, potentially leading to a significant role of informed speculation in the diagnostic process to help account for uncertainty.

In contrast, some organic disorders are diagnosed on a more general process of inductive inference. As Gagnon et al. (2006) note, socially challenging or inappropriate behaviour is often diagnosed as organic personality disorder following a brain lesion without establishing that the particular lesion is causally responsible for the change or that personality difficulties were not present before the brain injury occurred. Evidence suggests that personality change can occur regardless of lesion location although personality change is more common in those with pre-frontal cortex lesions (Barrash et al., 2011). However, the process of attributing the cause to a specific lesion, rendering it 'organic personality change', is under-determined by the presence of a lesion itself. This is particularly in light of the wide range of biopsychosocial factors that can lead to personality change after the experience of brain injury (Yeates et al., 2008). In law, the process of attributing cause is conceptualised as the 'but for test' where causation is granted where the outcome would not occur 'but for' the injury, although even with this depth of examination, considerable ambiguity can remain (Morse, 1995). Hence, a diagnosis of 'organic personality change' requires a separation of 'organic' causes from 'psychological' ones, before ordering them into a hierarchy of likely importance which can only be made on a 'most likely' basis.

\section{Erratic use and interpretation in clinical practice}

Considering there are no accepted criteria for distinguishing 'functional' from 'organic' problems across diagnoses, nor are there reliable concepts to which the terms apply across all use cases, one question is how clinicians understand the terms and concepts they regularly use. Given the importance of the functional-organic distinction for diagnosis and the 
prioritisation of treatment, it is perhaps surprising this has not been researched more widely. However, some existing studies have examined the question.

A mixed-methods study by Kanaan et al. (2012) asked neurologists what they understood by the term 'functional'. Survey options included "Abnormal brain function", "Abnormal body function", "Psychiatric problem", and "Not organic". The results are reproduced in Table 1 but notably all options were considered to be valid meanings of 'functional' by at least $20 \%$ of respondents with "not organic" being the most frequently chosen with many respondents choosing several meanings.

\begin{tabular}{lcc}
\hline \multicolumn{1}{c}{ Selection } & $\begin{array}{c}\text { Proportion }(\%) \\
\text { choosing the selection } \\
\text { at all }\end{array}$ & $\begin{array}{c}\text { Proportion (\%) of those } \\
\text { choosing only that selection }\end{array}$ \\
\hline Abnormal brain function & $127 / 349(36 \%)$ & $45 / 127(35 \%)$ \\
Abnormal body function & $77 / 349(22 \%)$ & $17 / 77(22 \%)$ \\
Psychiatric problem & $104 / 349(30 \%)$ & $29 / 104(28 \%)$ \\
Not organic & $216 / 349(62 \%)$ & $128 / 216(59 \%)$ \\
\hline
\end{tabular}

Table 1. Responses to survey question by neurologists on the meaning of 'functional' from Kanaan et al. (2012)

An earlier study by Kanaan et al. (2009) conducted in-depth interviews with consultant neurologists about how they understood conversion disorder - perhaps the paradigmatic functional disorder for neurologists. They endorsed psychological models of causation but didn't feel that it was their role to derive a psychological explanation and didn't clearly distinguish involuntary symptoms from deliberately feigning and deception under this definition.

A survey by Mace and Trimble (1991) asked 168 British neurologists which terminology they preferred for syndromes that lack a physical explanation for the symptoms and also included a question on which syndromes should be classified as 'functional'. The top three responses covered a remarkably wide range and included "pseudoseizures" (68\%) - episodes that typically resemble tonic-clonic seizures but without accompanying seizure activity in the brain, "anxiety neurosis" (62\%) - psychiatric disorders of disabling anxiety, and "Munchausen's syndrome" $(61 \%)$ - a form of illness deception involving the conscious presentation of sham symptoms.

A survey of 391 Canadian psychiatrists and psychiatric residents by Benrimoh et al. (2018) asked respondents to give opinions on the use of the phrase "organic causes" in their clinical work, and in psychiatry more generally. Over half of respondents $(55.9 \%)$ reported they used the phrase regularly. There was considerable variation in whether the phrase was considered 
stigmatising, implied dualism, or led to unhelpful treatment by the medical system. Indeed, while almost $56 \%$ of psychiatrists reported using it regularly, far fewer (just under 30\%) thought its use was appropriate. Many reported using it due to its assumed pragmatic function within the healthcare system, assuming, for example, that other clinicians would dismiss psychiatric patients' reports of physical health symptoms unless they communicated 'organic' causation on the patients' behalf.

Although small in number, these studies suggest that clinicians do not have a clear or consistent conceptual basis when interpreting or deploying the terms 'functional' and 'organic', despite using them frequently.

\section{Cultural perceptions and political uses}

The functional-organic distinction has an important political dimension as attributing causes at the level of mind and body, to give a typical lay reading, or to 'functional' or 'organic', in its broader and more complex bio-medical application, imply very different things about the patient's autonomy, responsibility and deservedness with 'organic' disorders seen as more deserving of care and individuals less responsible for their predicament (Greco, 2019; Miresco and Kirmayer, 2006). The distinction also affects the prestige of the illness, with 'organic' disorders considered more prestigious than 'functional' disorders by both professionals and the public (Album and Westin, 2008; Rosoff and Leone, 1991) and with the prestige conferred on relevant medical specialities tending to reflect this same hierarchy (Norredam and Album, 2007).

The functional-organic distinction is also a basis for challenging medical authority. Challenges to the legitimacy of psychiatry have frequently suggested that valid medical specialities are necessarily identified by their focus on 'organic' conditions (Breggin, 2019; Szasz, 2011) with some authors explicitly adopting the functional-organic distinction to argue against the legitimacy of psychiatric practice in the domain of 'functional' diagnoses (Awenat et al., 2013; Johnstone and Boyle, 2018) although seemingly without a critical insight into the difficulties inherent in this distinction itself. Similarly, most debates over the legitimacy of syndromes included under the broad category of 'medically unexplained symptoms' tend to involve grassroots patient pressure to accept a largely or solely 'organic' explanation for the symptoms (Greco, 2012). Examples where patients lobby for non-organic explanations of controversial syndromes are far harder to come by.

\section{Implications}

The functional-organic distinction is unhelpfully linear and unhelpfully static

One of the notable things about the functional-organic distinction is its implied commitment to 'zero sum' causality (Kendler, 2012). 'Functional' and 'organic' aetiology is conceived as if attributing more 'organic' causality necessarily implies the attribution of less 'functional' causality. This is apparent in the concept of "functional overlay" (Carter, 1967; Florence and Miller, 1985) where a certain proportion of the total presentation is attributed to either 'organic' or 'functional' aetiology, and the wide-ranging discussion of differential diagnosis between syndromes apparently on either side of the aetiological distinction (e.g. Pandey et 
al., 2014; Pruszewicz et al., 1991; Richter, 1991). These diagnostic categories imply syndromes exist in "purely functional" or "purely organic" equivalents, presumably representing the far ends of a functional-organic spectrum.

This conceptualisation largely rejects a dynamic relationship between neurological disorder, experience, behaviour, and context. This is despite the fact that the interaction between neurocognitive capacity, perception, affect, action, and context is perhaps one of the central assumptions of the neurocognitive sciences (Caramazza, 1992; Churchland and Sejnowski, 1988; Halligan and David, 2001; Mesulam, 2000; Shallice, 1988). These dynamic considerations become starker still when considering the range of difficulties likely to be analysed in terms of potential 'functional' and 'organic' components. While functions like memory may provide a relatively straightforward case (and are clearly complicated enough as they are), emotional responses and related psychiatric disorders become more complex still.

Taking depression as an example, it is very likely that the risk of depression after stroke is raised by damage to brain circuits involved in the control of emotion (Loubinoux et al., 2012) and although there may be instances of post-stroke depression which are almost entirely accounted for these brain changes, the causal factors for the majority of patients are likely to include a dynamic interaction between personal, social and neuropathological factors (Robinson and Jorge, 2015; Werheid, 2016; Whyte and Mulsant, 2002). Here, it is clear there is a marked disconnect between the best available science on the causes of depression after neurological disorder and the extent to which the functional-organic distinction can encapsulate these complex causal pathways, either through formal diagnoses or as a way of 'apportioning causality'.

Current diagnostic technology defines the limits of the functional-organic distinction Another limitation of the functional-organic distinction is its reliance on clinical diagnostic technology as an arbiter of what is considered 'organic'. Consequently, its limits lie within the extent to which this technology can detect neuropathology on an individual basis, rather than the best available science on likely causation.

In several instances, we know that damage to the nervous system is a major contributor to causality but because clinical diagnosis is unable to measure its presence and the relevant syndromes are rarely considered 'organic'. For example, Haag et al.'s (2019) review of brain injury in women subject to intimate partner violence report a prevalence of between $19 \%$ and $75 \%$ - most commonly in the form of mild traumatic brain injury where no changes can be detected on diagnostic neuroimaging. However, brain changes can be detected in group studies as altered cognition and disturbed functional connectivity (Valera and Kucyi, 2017). More generally, the neuropathological contributions to mild traumatic brain injury have been well-established (Romeu-Mejia et al., 2019) and the increased risk of mental health problems confidently identified (Perry et al., 2016). Nevertheless, the mental health consequences of intimate partner violence is almost always conceptualised in terms of social and emotional causality, with no mention of brain injury (Beydoun et al., 2016; Stewart and Vigod, 2019). Importantly, this is not simply a matter for researchers and the development of better 
theoretical models. A clinician who is presented with someone who has mental health problems for which mild traumatic brain injury has been a significant causal factor will be unable to confidentially establish any 'organic' changes through neurological examination because such damage does not lead to neuropathology than can be currently detected on an individual basis (Asken, 2019).

It is also worth noting the reverse scenario, where clinical diagnostics regularly result in evidence for neuropathology that is often dismissed as aetiologically irrelevant despite good evidence that it is a risk factor for poor functioning and poor mental health. For example, clinically abnormal computed tomography (CT) or magnetic resonance imagining (MRI) findings are present in high proportions of individuals with first episode psychosis $(64.2 \%$ Khandanpour et al. 2013; 17.6\% - Strahl et al. 2010; 19.2\% - Goulet et al. 2009). The vast majority of these findings are small but detectable pathologies, typically white matter hyperintensities, that are frequently dismissed as 'not clinically relevant'. This is despite the fact that exactly these changes have been found to predict mental health problems, poor outcome for mental health problems (Firth et al., 2019; Grangeon et al., 2010; Kieseppä et al., 2014; Wadhwa et al., 2019) and poor cognition (Moura et al., 2019) in otherwise neurologically unaffected adults across the lifespan.

We note psychosis is typically considered a 'functional' disorder, a framing which we speculate might at least partly account for why such clinical neurological findings are more likely to be dismissed in terms of explaining causality. But we also note the criterion for which abnormal findings were considered 'organic' and aetiologically relevant to psychosis in these studies (Goulet et al., 2009; Khandanpour et al., 2013; Strahl et al., 2010), namely that they were of a nature that 'changed clinical management' - presumably leading to a referral to neurologists for additional treatment. Here, 'organic' is not signifying the best evidence for likely causality but indicating a need to change clinical management.

\section{Social power in definition and application}

Epistemic and testimonial injustice refers to the situation where a person's testimony and the credibility of their claims are questioned on the basis of negative stereotypes (Fricker, 2007). Kidd and Carel (2017) have cited ill persons as particularly likely to be subjective to testimonial injustice, due to wide-ranging stereotypes about the effect of pathologies on individuals. Neurological disorders can obviously affect the accuracy of someone's testimony (for example, through memory deficits). However, as Kidd and Carel (2017) note, this does not change the fact that people with neurological disorders may still be subject to unjustified dismissals of valid concerns based on inaccurate ideas about personal unreliability.

We note here the significant potential for epistemic injustice given common stereotypes about 'functional' and 'organic' illnesses in terms of autonomy, responsibility and deservedness (Greco, 2019). Research on carer and professional perceptions of 'challenging' behaviour in survivors of brain injury show clear evidence for the active construction of the causes of behaviour (Holloway et al., 2019; Tam et al., 2015). Here, the extent to which the person's troubling behaviour is given a 'brain injury' or 'intentional' explanation depends heavily on 
the motivations of the individual doing the interpretation. Huet et al. (2018) reported exactly this process of active interpretation by health professionals who tended to reframe aggressive and angry behaviour as involuntary, thereby maintaining a 'good person' understanding of the patient. However, this interpretation also has the potential to erase any valid frustrations or concerns that may have motivated the behaviour and renders the individual socially inert.

Although not widely researched, we note that the concept of 'inappropriate' or 'challenging' behaviour relies heavily on social and cultural norms and has the potential to raise important ethical issues. Cases of changes in sexual preference and sexual orientation after brain injury have been interpreted in terms of pathological alteration to the brain circuits mediating sexual preference (Miller et al., 1986). But it is also possible that the brain injury altered the capacity to strategically inhibit pre-existing desires, or that the change was a conscious decision after an important life event, although these latter interpretations require a starker form of social attribution that may involve re-evaluating, rightly or wrongly, the person in question, depending on others' approval of their new behaviour. We note that changes subject to fewer prejudices and typically seen in more benign light, such as a sudden interest in producing art after brain injury, are usually explained in terms of 'disinhibition' (Midorikawa and Kawamura, 2015; Pollak et al., 2007) which has the function of attributing the new socially acceptable activity to the 'self' rather than to pathology, which has simply 'released' it.

Common to these accounts is that the testimony of patients features little in the explanation of the behaviour and we suggest that this situation occurs frequently in the process of providing both clinical accounts and scientific explanations. Furthermore, we also note that the testimony of people affected by neurological and neuropsychiatric conditions is almost entirely absent from the scientific and clinical debates that have formed the conceptual basis of the functional-organic distinction. Here, we argue that inclusion of first-person perspectives is essential to inform several important areas of practice and scientific understanding.

Firstly, it would inform clinical work in terms of better understanding the process of being subject to the functional-organic distinction, how it is perceived, experienced and understood by patients. Secondly, in terms of scientific understanding, it would provide a phenomenology of experience to better understand the interaction between, for example, injury and autonomy. These approaches are now commonplace in psychiatry, where understanding experience is considered to be a central component in advancing the development and delivery of health care systems (e.g. Katsakou and Priebe, 2007) and where understanding subjective experience informs neuropsychological theories of causation (e.g. Uhlhaas and Mishara, 2007). Although some studies have been conducted on the experience of health care, as far as we know, no research has ever been conducted with, for example, survivors of brain injury that aims to inform the science of how neurological-level and personal-level processes interact.

It is also the case that the priorities of people who use healthcare systems may differ markedly from the priorities of healthcare systems themselves. Similarly, the research 
priorities of researchers and patients have been found to differ substantially (Selby et al., 2012). We note here that the functional-organic distinction is a conceptual tool developed by medicine to try and solve a particular set of problems, but one important focus of research should be to investigate how well these problems actually map onto the priorities of those seeking help.

\section{Conclusions}

So, what is the functional-organic distinction actually doing in psychiatry and neurology? From what we have discussed above, it is perhaps worth noting what it is not doing. It is not reliably distinguishing between aetiology at different levels (physiological, psychological etc) across contexts. Indeed, the extent to which it can reliably distinguish between types of causes for particular signs, symptoms and syndromes seems to differ depending on the signs, symptoms and syndromes being assessed. In some cases, conceptual inconsistencies and difficulties with practical diagnosis render this an ambition rather than a reliable outcome, partly due to the multiplicity of meanings represented by the terms themselves. Rather than a general distinction, it is more akin to various local distinctions, each defined and limited by context.

Importantly, it seems that one of the major functions of this distinction is to provide a justification and language to allow clinicians to prioritise healthcare interventions. Indeed, considering the complex nature of neuropsychiatric disorders where causes are likely dynamic, reciprocal and span levels of explanation, the functional-organic distinction often seems like a tool that helps determine treatment priority dressed up in the language of causation. To reiterate, it is clear that there are syndromes almost entirely accounted for by diagnosable pathophysiological changes, and those that are not, but most neuropsychiatric disorders are not at these extremes, and are caused by multiple interacting factors.

Rhetorically, however, talk of 'organic' causation retains a caché, influence and credibility that 'functional' causation does not, and it is clear that this rhetoric is used strategically by healthcare professionals to work within healthcare systems - mostly, it must be said, in good faith attempts to provide effective care. Nevertheless, the extent to which the strategic simplification and complex scientific reality influence and limit each other should be more widely investigated.

Perhaps most striking is the fact that these debates almost entirely exclude the priorities and experiences of those most affected by them - namely patients with challenges of mind, brain, emotion, behaviour, and society, whose difficulties are interpreted in terms of 'functional' and 'organic' components. We highlight how the inclusion of these perspectives are likely to be essential for better science and better healthcare in this area. 


\section{Acknowledgements}

Many thanks for Prof Adam Zeman for helpful comments during the preparation of this manuscript. 


\section{References}

Album, D., Westin, S., 2008. Do diseases have a prestige hierarchy? A survey among physicians and medical students. Social Science \& Medicine 66, 182-188. https://doi.org/10.1016/j.socscimed.2007.07.003

Amad, A., Fovet, T., Geoffroy, P.A., 2015. Keep calm: Psychiatric disorders are organic! The power of words in medicine: https://doi.org/10.1177/0004867415601730

Arráez-Aybar, L.-A., Navia-Álvarez, P., Fuentes-Redondo, T., Bueno-López, J.-L., 2015. Thomas Willis, a pioneer in translational research in anatomy (on the 350th anniversary of Cerebri anatome). J Anat 226, 289-300. https://doi.org/10.1111/joa.12273

Asken, B.M., 2019. Concussion Biomarkers: Deviating From the Garden Path. JAMA Neurol 76, 515-516. https://doi.org/10.1001/jamaneurol.2019.0125

Awenat, F., Berger, B., Coles, S., Dooley, C., Foster, S., Hanna, J., Hemmingfield, J., Johnstone, L., Nadirshaw, Z., Wainwright, T., 2013. Classification of behaviour and experience in relation to functional psychiatric diagnoses: Time for a paradigm shift. Leicester: British Psychological Society.

Baizabal-Carvallo, J.F., Fekete, R., 2015. Recognizing Uncommon Presentations of Psychogenic (Functional) Movement Disorders. Tremor Other Hyperkinet Mov (N Y) 5. https://doi.org/10.7916/D8VM4B13

Barrash, J., Asp, E., Markon, K., Manzel, K., Anderson, S.W., Tranel, D., 2011. Dimensions of personality disturbance after focal brain damage: Investigation with the Iowa Scales of Personality Change. Journal of Clinical and Experimental Neuropsychology 33, 833-852. https://doi.org/10.1080/13803395.2011.561300

Beer, M.D., 1996a. The dichotomies: psychosis/neurosis and functional/organic: a historical perspective. Hist Psychiatry 7, 231-255. https://doi.org/10.1177/0957154X9600702603

Beer, M.D., 1996b. The endogenous psychoses: a conceptual history. Hist Psychiatry 7, 001029. https://doi.org/10.1177/0957154X9600702501

Benrimoh, D., Pomerleau, V.J., Demoustier, A., Poulin, S., Maltais, J.-R., Brouillette, J., Ducharme, S., 2018. Why We Still Use "Organic Causes": Results From a Survey of Psychiatrists and Residents. JNP 31, 57-64. https://doi.org/10.1176/appi.neuropsych.18050099

Berrios, G.E., Beer, D., 1994. The notion of unitary psychosis: a conceptual history. Hist Psychiatry 5, 013-036. https://doi.org/10.1177/0957154X9400501702

Berrios, G.E., Luque, R., Villagrán, J.M., 2003. Schizophrenia: a conceptual history. International Journal of Psychology and Psychological Therapy 3, 111-140.

Berry, H., 2000. Chronic Whiplash Syndrome as a Functional Disorder. Arch Neurol 57, 592-594. https://doi.org/10.1001/archneur.57.4.592

Beydoun, H.A., Williams, M., Beydoun, M.A., Eid, S.M., Zonderman, A.B., 2016. Relationship of Physical Intimate Partner Violence with Mental Health Diagnoses in the Nationwide Emergency Department Sample. Journal of Women's Health 26, 141151. https://doi.org/10.1089/jwh.2016.5840

Breggin, P.R., 2019. Extreme Psychospiritual States Versus Organic Brain Disease: Bringing Together Science and the Human Factor. Journal of Humanistic Psychology 59, 686696. https://doi.org/10.1177/0022167818761975

Caramazza, A., 1992. Is Cognitive Neuropsychology Possible? Journal of Cognitive Neuroscience 4, 80-95. https://doi.org/10.1162/jocn.1992.4.1.80

Carter, A.B., 1967. THE FUNCTIONAL OVERLAY. The Lancet 290, 1196-1200. https://doi.org/10.1016/S0140-6736(67)91909-5 
Churchland, P.S., Sejnowski, T.J., 1988. Perspectives on cognitive neuroscience. Science 242, 741-745. https://doi.org/10.1126/science.3055294

Cornish, F., Gillespie, A., 2009. A Pragmatist Approach to the Problem of Knowledge in Health Psychology: Journal of Health Psychology. https://doi.org/10.1177/1359105309338974

Cullen, W., 1780. Synopsis nosologiae methodicae.

David, A.S., 2009. Basic Concepts in Neuropsychiatry. Lishman's Organic Psychiatry: A Textbook of Neuropsychiatry 1-27.

Demartini, B., Ricciardi, L., Parees, I., Ganos, C., Bhatia, K.P., Edwards, M.J., 2015. A positive diagnosis of functional (psychogenic) tics. European Journal of Neurology 22, 527-e36. https://doi.org/10.1111/ene.12609

Edwards, M.J., Stone, J., Lang, A.E., 2014. From psychogenic movement disorder to functional movement disorder: It's time to change the name. Movement Disorders 29, 849-852. https://doi.org/10.1002/mds.25562

Enzenauer, R., Morris, W., O’Donnell, T., Montrey, J., 2014. Terminology of Functional Disorders, in: Enzenauer, R., Morris, W., O’Donnell, T., Montrey, J. (Eds.), Functional Ophthalmic Disorders: Ocular Malingering and Visual Hysteria. Springer International Publishing, Cham, pp. 1-10. https://doi.org/10.1007/978-3-319-087504_1

Espay, A.J., Aybek, S., Carson, A., Edwards, M.J., Goldstein, L.H., Hallett, M., LaFaver, K., LaFrance, W.C., Lang, A.E., Nicholson, T., Nielsen, G., Reuber, M., Voon, V., Stone, J., Morgante, F., 2018. Current Concepts in Diagnosis and Treatment of Functional Neurological Disorders. JAMA Neurol 75, 1132-1141. https://doi.org/10.1001/jamaneurol.2018.1264

Farre, J.M., Fora, F., Lasheras, M.G., 2004. Specific aspects of erectile dysfunction in psychiatry. Int J Impot Res 16, S46-S49. https://doi.org/10.1038/sj.ijir.3901243

Fauman, M.A., 1977. A diagnostic system for organic brain disorders: Critique and suggestion. Psych Quart 49, 173-186. https://doi.org/10.1007/BF01115313

Firth, Josh, Smith, L., Sarris, J., Vancampfort, D., Schuch, F., Carvalho, A., Solmi, M., Yung, A., Stubbs, B., Firth, Joseph, 2019. Handgrip strength is associated with hippocampal volume and white matter hyperintensities in major depression and healthy controls: a U.K. Biobank study. Psychosomatic Medicine Publish Ahead of Print. https://doi.org/10.1097/PSY.0000000000000753

Florence, D.W., Miller, T.C., 1985. Functional overlay in work-related injury. Postgraduate Medicine 77, 97-108. https://doi.org/10.1080/00325481.1985.11699028

Fricker, M., 2007. Epistemic injustice: Power and the ethics of knowing. Oxford University Press.

Fryar-Williams, S., Strobel, J.E., 2016. Biomarker Case-Detection and Prediction with Potential for Functional Psychosis Screening: Development and Validation of a Model Related to Biochemistry, Sensory Neural Timing and End Organ Performance. Front. Psychiatry 7. https://doi.org/10.3389/fpsyt.2016.00048

Gagnon, J., Bouchard, M., Rainville, C., 2006. Differential diagnosis between borderline personality disorder and organic personality disorder following traumatic brain injury. Bulletin of the Menninger Clinic 70, 1-28. https://doi.org/10.1521/bumc.2006.70.1.1

Geffken, G.R., Ward, H.E., Staab, J.P., Carmichael, S.L.K., Evans, D.L., 1998. PSYCHIATRIC MORBIDITY IN ENDOCRINE DISORDERS. Psychiatric Clinics of North America 21, 473-489. https://doi.org/10.1016/S0193-953X(05)70017-4

Goetz, C.G., 2009. Chapter 15 Jean-Martin Charcot and the anatomo-clinical method of neurology, in: Aminoff, M.J., Boller, F., Swaab, D.F. (Eds.), Handbook of Clinical 
Neurology, History of Neurology. Elsevier, pp. 203-212.

https://doi.org/10.1016/S0072-9752(08)02115-5

Gomis, M., Puente, V., Pont-Sunyer, C., Oliveras, C., Roquer, J., 2008. Adult onset simple phonic tic after caudate stroke. Movement Disorders 23, 765-766.

https://doi.org/10.1002/mds.21955

Goulet, K., Deschamps, B., Evoy, F., Trudel, J.-F., 2009. Use of Brain Imaging (Computed Tomography and Magnetic Resonance Imaging) in First-Episode Psychosis: Review and Retrospective Study. Can J Psychiatry 54, 493-501. https://doi.org/10.1177/070674370905400711

Gowers, W.R., 1898. A manual of diseases of the nervous system. P. Blakiston, Son \& Company.

Grangeon, M.C., Seixas, C., Quarantini, L.C., Miranda-Scippa, A., Pompili, M., Steffens, D.C., Wenzel, A., Lacerda, A.L.T., de Oliveira, I.R., 2010. White matter hyperintensities and their association with suicidality in major affective disorders: a meta-analysis of magnetic resonance imaging studies. CNS Spectr 15, 375-381.

Greco, M., 2019. On illness and value: biopolitics, psychosomatics, participating bodies. Medical Humanities 45, 107-115. https://doi.org/10.1136/medhum-2018-011588

Greco, M., 2012. The classification and nomenclature of 'medically unexplained symptoms': Conflict, performativity and critique. Social Science \& Medicine, Part Special Issue: Place, migration \& health 75, 2362-2369. https://doi.org/10.1016/j.socscimed.2012.09.010

Haag, H. (Lin), Jones, D., Joseph, T., Colantonio, A., 2019. Battered and Brain Injured: Traumatic Brain Injury Among Women Survivors of Intimate Partner Violence-A Scoping Review. Trauma, Violence, \& Abuse 1524838019850623. https://doi.org/10.1177/1524838019850623

Halligan, P.W., David, A.S., 2001. Cognitive neuropsychiatry: towards a scientific psychopathology. Nat Rev Neurosci 2, 209-215. https://doi.org/10.1038/35058586

Holloway, M., Orr, D., Clark-Wilson, J., 2019. Experiences of challenges and support among family members of people with acquired brain injury: a qualitative study in the UK. Brain Injury 33, 401-411. https://doi.org/10.1080/02699052.2019.1566967

Huet, M., Dany, L., Apostolidis, T., 2018. Explain the 'unexplainable': A qualitative enquiry of the representations of the caregivers of brain-injured people. J Health Psychol 23, 1050-1062. https://doi.org/10.1177/1359105316642834

Johnstone, L., Boyle, M., 2018. The Power Threat Meaning Framework: An Alternative Nondiagnostic Conceptual System. Journal of Humanistic Psychology 0022167818793289. https://doi.org/10.1177/0022167818793289

Kahn, R.M., Arbib, M.A., 1973. A cybernetic approach to childhood psychosis. J Autism Dev Disord 3, 261-273. https://doi.org/10.1007/BF01538284

Kanaan, R., Armstrong, D., Barnes, P., Wessely, S., 2009. In the psychiatrist's chair: how neurologists understand conversion disorder. Brain 132, 2889-2896. https://doi.org/10.1093/brain/awp060

Kanaan, R.A., Armstrong, D., Wessely, S.C., 2012. The function of 'functional': a mixed methods investigation. J Neurol Neurosurg Psychiatry 83, 248-250. https://doi.org/10.1136/jnnp-2011-300992

Katsakou, C., Priebe, S., 2007. Patient's experiences of involuntary hospital admission and treatment: A review of qualitative studies. Epidemiology and Psychiatric Sciences 16, 172-178. https://doi.org/10.1017/S1121189X00004802

Kendler, K.S., 2012. The dappled nature of causes of psychiatric illness: replacing the organic-functional/hardware-software dichotomy with empirically based pluralism. Mol Psychiatry 17, 377-388. https://doi.org/10.1038/mp.2011.182 
Khandanpour, N., Hoggard, N., Connolly, D.J.A., 2013. The role of MRI and CT of the brain in first episodes of psychosis. Clinical Radiology 68, 245-250. https://doi.org/10.1016/j.crad.2012.07.010

Kidd, I.J., Carel, H., 2017. Epistemic Injustice and Illness. Journal of Applied Philosophy 34, 172-190. https://doi.org/10.1111/japp.12172

Kieseppä, T., Mäntylä, R., Tuulio-Henriksson, A., Luoma, K., Mantere, O., Ketokivi, M., Holma, M., Jylhä, P., Melartin, T., Suominen, K., Vuorilehto, M., Isometsä, E., 2014. White matter hyperintensities and cognitive performance in adult patients with bipolar I, bipolar II, and major depressive disorders. European Psychiatry 29, 226-232. https://doi.org/10.1016/j.eurpsy.2013.08.002

Krauss, J.K., Jankovic, J., 1997. Tics secondary to craniocerebral trauma. Movement Disorders 12, 776-782. https://doi.org/10.1002/mds.870120527

Kwak, C.H., Jankovic, J., 2002. Tourettism and dystonia after subcortical stroke. Movement Disorders 17, 821-825. https://doi.org/10.1002/mds.10207

Lee, S., Gottlieb, M., Mulhausen, P., Wilbur, J., Reisinger, H.S., Han, J.H., Carnahan, R., 2019. Recognition, prevention, and treatment of delirium in emergency department: An evidence-based narrative review. The American Journal of Emergency Medicine. https://doi.org/10.1016/j.ajem.2019.158454

Lewis, B., 2007. The Biopsychosocial Model and Philosophic Pragmatism: Is George Engel a Pragmatist? Philosophy, Psychiatry, \& Psychology 14, 299-310. https://doi.org/10.1353/ppp.0.0142

Lipowski, Z.J., 1985. Organic Brain Syndromes, in: Lipowski, Z.J. (Ed.), Psychosomatic Medicine and Liaison Psychiatry: Selected Papers. Springer US, Boston, MA, pp. 235-245. https://doi.org/10.1007/978-1-4613-2509-3_13

Loubinoux, I., Kronenberg, G., Endres, M., Schumann-Bard, P., Freret, T., Filipkowski, R.K., Kaczmarek, L., Popa-Wagner, A., 2012. Post-stroke depression: mechanisms, translation and therapy. Journal of Cellular and Molecular Medicine 16, 1961-1969. https://doi.org/10.1111/j.1582-4934.2012.01555.x

Mace, C.J., Trimble, M.R., 1991. "Hysteria", "functional" or "psychogenic"? A survey of British neurologists' preferences. J R Soc Med 84, 471-475.

Maguire, M., Singh, J., Marson, A., 2018. Epilepsy and psychosis: a practical approach. Practical Neurology 18, 106-114. https://doi.org/10.1136/practneurol-2017-001775

Martin, J.B., 2002. The Integration of Neurology, Psychiatry, and Neuroscience in the 21st Century. AJP 159, 695-704. https://doi.org/10.1176/appi.ajp.159.5.695

Mesulam, M.-M., 2000. Principles of behavioral and cognitive neurology. Oxford University Press.

Midorikawa, A., Kawamura, M., 2015. The emergence of artistic ability following traumatic brain injury. Neurocase 21, 90-94. https://doi.org/10.1080/13554794.2013.873058

Miller, B.L., Cummings, J.L., McIntyre, H., Ebers, G., Grode, M., 1986. Hypersexuality or altered sexual preference following brain injury. Journal of Neurology, Neurosurgery \& Psychiatry 49, 867-873. https://doi.org/10.1136/jnnp.49.8.867

Miresco, M.J., Kirmayer, L.J., 2006. The Persistence of Mind-Brain Dualism in Psychiatric Reasoning About Clinical Scenarios. AJP 163, 913-918. https://doi.org/10.1176/ajp.2006.163.5.913

Molnár, Z., 2004. Thomas Willis (1621-1675), the founder of clinical neuroscience. Nat Rev Neurosci 5, 329-335. https://doi.org/10.1038/nrn1369

Morse, S.J., 1995. Brain and Blame Essay. Geo. L.J. 84, 527-550.

Moura, A.R., Lee, S., Habeck, C., Razlighi, Q., Stern, Y., 2019. The relationship between white matter hyperintensities and cognitive reference abilities across the life span. 
Neurobiology of Aging 83, 31-41.

https://doi.org/10.1016/j.neurobiolaging.2019.08.024

Norredam, M., Album, D., 2007. Review Article: Prestige and its significance for medical specialties and diseases. Scand J Public Health 35, 655-661.

https://doi.org/10.1080/14034940701362137

Pandey, S., Nahab, F., Aldred, J., Nutt, J., Hallett, M., 2014. Post-Traumatic Shoulder Movement Disorders: A Challenging Differential Diagnosis Between Organic and Functional. Movement Disorders Clinical Practice 1, 102-105. https://doi.org/10.1002/mdc3.12016

Perry, D.C., Sturm, V.E., Peterson, M.J., Pieper, C.F., Bullock, T., Boeve, B.F., Miller, B.L., Guskiewicz, K.M., Berger, M.S., Kramer, J.H., Welsh-Bohmer, K.A., 2016.

Association of traumatic brain injury with subsequent neurological and psychiatric disease: a meta-analysis. Journal of Neurosurgery 124, 511-526. https://doi.org/10.3171/2015.2.JNS14503

Pollak, T.A., Mulvenna, C.M., Lythgoe, M.F., 2007. De novo Artistic Behaviour following Brain Injury. Neurological Disorders in Famous Artists - Part 2 22, 75-88. https://doi.org/10.1159/000102873

Pruszewicz, A., Obrebowski, A., świdziński, P., Demeńko, G., Wika, T., Wojciechowska, A., 1991. Usefulness of Acoustic Studies on the Differential Diagnostics of Organic and Functional Dysphonia. Acta Oto-Laryngologica 111, 414-419. https://doi.org/10.3109/00016489109137412

Pylyshyn, Z.W., 1978. Computational models and empirical constraints. Behavioral and Brain Sciences 1, 91-99. https://doi.org/10.1017/S0140525X00059793

Ranjan, N., Nair, K.P.S., Romanoski, C., Singh, R., Venketswara, G., 2011. Tics after traumatic brain injury. Brain Injury 25, 629-633. https://doi.org/10.3109/02699052.2011.572944

Reynolds, E.H., 1990. Structure and Function in Neurology and Psychiatry. The British Journal of Psychiatry 157, 481-490. https://doi.org/10.1192/bjp.157.4.481

Richter, J.E., 1991. Dyspepsia: Organic Causes and Differential Characteristics from Functional Dyspepsia. Scandinavian Journal of Gastroenterology 26, 11-16. https://doi.org/10.3109/00365529109109531

Robinson, R.G., Jorge, R.E., 2015. Post-Stroke Depression: A Review. AJP 173, 221-231. https://doi.org/10.1176/appi.ajp.2015.15030363

Romeu-Mejia, R., Giza, C.C., Goldman, J.T., 2019. Concussion Pathophysiology and Injury Biomechanics. Curr Rev Musculoskelet Med 12, 105-116. https://doi.org/10.1007/s12178-019-09536-8

Rosoff, S.M., Leone, M.C., 1991. The public prestige of medical specialties: Overviews and undercurrents. Social Science \& Medicine 32, 321-326. https://doi.org/10.1016/02779536(91)90110-X

Sachdev, P., 1996. A critique of 'organic' and its proposed alternatives. Australian and New Zealand Journal of Psychiatry 30, 165-170. https://doi.org/10.3109/00048679609076090

Sanders, J.L., 2011. A Distinct Language and a Historic Pendulum: The Evolution of the Diagnostic and Statistical Manual of Mental Disorders. Archives of Psychiatric Nursing 25, 394-403. https://doi.org/10.1016/j.apnu.2010.10.002

Selby, J.V., Beal, A.C., Frank, L., 2012. The Patient-Centered Outcomes Research Institute (PCORI) National Priorities for Research and Initial Research Agenda. JAMA 307, 1583-1584. https://doi.org/10.1001/jama.2012.500

Shallice, T., 1988. From neuropsychology to mental structure. Cambridge University Press. 
Silber, T.J., 1985. Functional disorders during adolescence. Medical Aspects of Human Sexuality 19, 42-57.

Starkstein, S.E., Rabins, P.V., Berthier, M.L., Cohen, B.J., Folstein, M.F., Robinson, R.G., 1989. Dementia of depression among patients with neurological disorders and functional depression. J Neuropsychiatry Clin Neurosci 1, 263-268. https://doi.org/10.1176/jnp.1.3.263

Stewart, D.E., Vigod, S.N., 2019. Update on Mental Health Aspects of Intimate Partner Violence. Medical Clinics of North America, Women's Mental Health 103, 735-749. https://doi.org/10.1016/j.mcna.2019.02.010

Stone, J., Zeman, A., Sharpe, M., 2002. Functional weakness and sensory disturbance. Journal of Neurology, Neurosurgery \& Psychiatry 73, 241-245. https://doi.org/10.1136/jnnp.73.3.241

Strahl, B., Cheung, Y.K., Stuckey, S.L., 2010. Diagnostic yield of computed tomography of the brain in first episode psychosis. Journal of Medical Imaging and Radiation Oncology 54, 431-434. https://doi.org/10.1111/j.1754-9485.2010.02196.x

Szasz, T., 2011. The myth of mental illness: 50 years later. The Psychiatrist 35, 179-182. https://doi.org/10.1192/pb.bp.110.031310

Tam, S., McKay, A., Sloan, S., Ponsford, J., 2015. The experience of challenging behaviours following severe TBI: A family perspective. Brain Injury 29, 813-821. https://doi.org/10.3109/02699052.2015.1005134

Trimble, M.R., 1982. Functional diseases. Br Med J (Clin Res Ed) 285, 1768-1770.

Tyrer, P., 2014. A comparison of DSM and ICD classifications of mental disorder. Advances in Psychiatric Treatment 20, 280-285. https://doi.org/10.1192/apt.bp.113.011296

Uhlhaas, P.J., Mishara, A.L., 2007. Perceptual Anomalies in Schizophrenia: Integrating Phenomenology and Cognitive Neuroscience. Schizophr Bull 33, 142-156. https://doi.org/10.1093/schbul/sbl047

Ungar, T., Knaak, S., 2013. The hidden medical logic of mental health stigma. Aust N Z J Psychiatry 47, 611-612. https://doi.org/10.1177/0004867413476758

Valera, E., Kucyi, A., 2017. Brain injury in women experiencing intimate partner-violence: neural mechanistic evidence of an "invisible" trauma. Brain Imaging and Behavior 11, 1664-1677. https://doi.org/10.1007/s11682-016-9643-1

Wadhwa, R., Wen, W., Frankland, A., Leung, V., Sinbandhit, C., Stuart, A., Dawes, L., Hadzi-Pavlovic, D., Levy, F., Lenrootl, R., Mitchell, P.B., Roberts, G., 2019. White matter hyperintensities in young individuals with bipolar disorder or at high genetic risk. Journal of Affective Disorders 245, 228-236. https://doi.org/10.1016/j.jad.2018.10.368

Werheid, K., 2016. A Two-Phase Pathogenetic Model of Depression after Stroke. GER 62, 33-39. https://doi.org/10.1159/000381876

Whyte, E.M., Mulsant, B.H., 2002. Post stroke depression: epidemiology, pathophysiology, and biological treatment. Biological Psychiatry 52, 253-264. https://doi.org/10.1016/S0006-3223(02)01424-5

Wilson, K., 1940. Neurology. Hafner Pub Co Inc, New York.

Wilson, L., Szigeti, A., Kearney, A., Clarke, M., 2018. Clinical characteristics of primary psychotic disorders with concurrent substance abuse and substance-induced psychotic disorders: A systematic review. Schizophrenia Research 197, 78-86. https://doi.org/10.1016/j.schres.2017.11.001

Yeates, D.G.N., Gracey, F., Mcgrath, J.C., 2008. A biopsychosocial deconstruction of "personality change" following acquired brain injury. Neuropsychological Rehabilitation 18, 566-589. https://doi.org/10.1080/09602010802151532 
Zeman, A., 2014. Neurology is psychiatry-and vice versa. Practical Neurology 14, 136-144. https://doi.org/10.1136/practneurol-2013-000761 